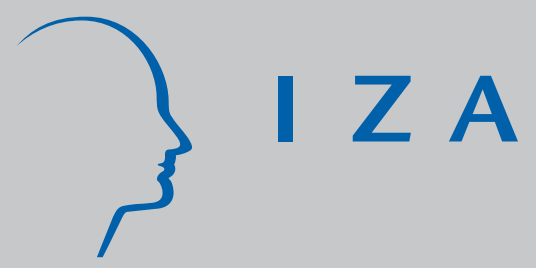

IZA DP No. 1163

The Effect of Unemployment Insurance on Unemployment Duration and the Subsequent Employment Stability

Konstantinos Tatsiramos

May 2004 


\title{
The Effect of Unemployment Insurance on Unemployment Duration and the Subsequent Employment Stability
}

\author{
Konstantinos Tatsiramos \\ European University Institute, \\ CentER, Tilburg University and IZA Bonn
}

Discussion Paper No. 1163

May 2004

substantially revised version available as:

IZA Discussion Paper No. 2280 (August 2006)

\author{
IZA \\ P.O. Box 7240 \\ 53072 Bonn \\ Germany \\ Phone: +49-228-3894-0 \\ Fax: +49-228-3894-180 \\ Email: iza@iza.org
}

\begin{abstract}
Any opinions expressed here are those of the author(s) and not those of the institute. Research disseminated by IZA may include views on policy, but the institute itself takes no institutional policy positions.

The Institute for the Study of Labor (IZA) in Bonn is a local and virtual international research center and a place of communication between science, politics and business. IZA is an independent nonprofit company supported by Deutsche Post World Net. The center is associated with the University of Bonn and offers a stimulating research environment through its research networks, research support, and visitors and doctoral programs. IZA engages in (i) original and internationally competitive research in all fields of labor economics, (ii) development of policy concepts, and (iii) dissemination of research results and concepts to the interested public.
\end{abstract}

IZA Discussion Papers often represent preliminary work and are circulated to encourage discussion. Citation of such a paper should account for its provisional character. A revised version may be available on the IZA website (www.iza.org) or directly from the author. 


\section{ABSTRACT \\ The Effect of Unemployment Insurance on Unemployment Duration and the Subsequent Employment Stability*}

This paper studies the effect of unemployment benefits on the unemployment and subsequent employment duration using individual data from the European Community Household Panel, for France, Germany, and the UK. The empirical analysis is based on a two-state mixed proportional hazard model allowing for flexible duration dependence and state specific unobserved heterogeneity. We find that recipients, relative to non-recipients, face lower exit rates from unemployment, while an additional month in unemployment increases their subsequent employment stability. This positive correlation between previous unemployment and subsequent employment duration for the recipients is statistically significant for the short-term unemployed in France and Germany. The results indicate that in these two countries, which provide more generous benefits relative to the UK, recipients who search for a longer period within the first year in unemployment obtain higher employment stability.

JEL Classification: J64, J65, C41

Keywords: unemployment insurance, unemployment duration, employment duration, duration analysis

Konstantinos Tatsiramos

European University Institute

Villa San Paolo

Via della Piazzuolla 43

50133 Florence

Italy

Email: Konstantinos.Tatsiramos@iue.it

\footnotetext{
* I wish to thank Andrea Ichino, Jan van Ours, and Karl Schlag, for valuable suggestions and comments. This paper has also benefited from discussions with Christian Belzil, Armin Falk, and seminar participants at the EUI, Tilburg, and the 7th IZA European Summer School in Labour Economics. Any remaining errors are only mine. Financial support from the European University Institute, the CentER at Tilburg University as a Marie Curie Training Site, and the Greek State Scholarship Foundation (IKY), is greatly acknowledged.
} 


\section{Introduction}

The purpose of this paper is to empirically assess the effect of Unemployment Insurance Benefits (UIB) on unemployment duration and on the duration of the subsequent employment. The role of Unemployment Insurance (UI) on labour market dynamics has attracted much attention in the last 30 years. The research has mainly focused on the effect of UIB on the transition out of unemployment. The theoretical analysis based on optimal job search theory suggests that benefits create disincentives. Recipients set a higher reservation wage and devote less search effort which lowers their exit rate from unemployment (Mortensen, 1977). The empirical literature has shown that benefits lead to longer unemployment spells. ${ }^{1}$

The effect of UI benefits is not limited only to the unemployment spell. Benefits can affect also the employment outcomes of the individuals on at least two dimensions. The first, refers to the effect of UIB on re-employment wages. Higher reservation wages due to benefits should be reflected on higher post-unemployment wages. The second, refers to the effect of UIB on the quality of the job match. In a theoretical study, Marimon and Zilibotti (1999), suggest that in a labour market with search frictions unemployment benefits tend to reduce job mismatch. That is, benefits which are seen as a "search subsidy" lower the opportunity cost of job search giving time to the unemployed to find not just a job, but "the right job" (Burdett, 1979).

In this paper, we are focusing on the effect of UI benefits on subsequent employment stability. ${ }^{2}$ The main hypothesis addressed is that if benefits give time to the unemployed to

\footnotetext{
${ }^{1}$ For a review of the empirical literature see Atkinson and Micklewright (1991), and Devine and Kiefer (1991).

${ }^{2}$ In what follows, we will focus on employment stability looking at the employment duration, which incorporates job to job transitions.
} 
obtain a good match, then this should imply a positive correlation between unemployment and subsequent employment duration for the recipients. Assuming that better matches in the labour market tend to last longer, identifying the effect of benefits on employment duration would provide us with information regarding the effect of UI benefits on the efficiency of the matching process.

The empirical literature on the effect of UIB on employment duration is very limited mainly due to the scarcity of large micro data sets which provide information both on labour market histories and on UI benefits, and has focused on Canadian and US data. (e.g., Belzil, 2001 ; Jurajda, 2002; Baker and Rea, 1998). ${ }^{3}$

We extend the previous literature by employing data from the European Community Household Panel (ECHP, 1994-2001) for three European countries, namely, France, Germany, and the UK. The ECHP is a survey based on a standardised questionnaire that involves annual interviewing of a representative panel of households and individuals in each EU country, which provides with variation in the receipt of benefits across the unemployed. We choose these countries because they provide different configuration of the labour market institutions. These differences mainly refer to the Employment Protection Legislation (EPL), which affects hiring and firing, and the UI system. In particular, France and Germany, provide more generous benefits, compared to the UK, and they are characterised by more strict employment protection. For each country, we obtain an inflow sample of unemployed and their subsequent employment history. ${ }^{4}$

The effect of UIB on unemployment duration is identified by comparing the exit rate

\footnotetext{
${ }^{3} \mathrm{~A}$ more detailed discussion of the theoretical and empirical literature is contained in Section 2.

${ }^{4}$ The data share similar features with the data in the study by Bover, Arellano, and Bentolila (2002), on the effect of UIB on unemployment duration in Spain.
} 
of unemployed with and without benefits given unemployment duration and controlling for other individual characteristics. The identification of the effect of UIB on employment duration is obtained by comparing the effect of previous unemployment duration between recipients and non-recipients. The econometric analysis is based on a two-state mixed proportional hazard model allowing for flexible duration dependence and state specific unobserved heterogeneity. The two states in the model are unemployment and subsequent employment. To control for endogeneity of previous unemployment duration on the subsequent employment duration, we estimate unemployment and employment durations jointly allowing the unobserved heterogeneity components to be correlated across the two states.

The results are in accordance with the empirical literature on the effect of UIB on unemployment duration. In particular, we find that recipients, relative to non-recipients, face lower exit rates from unemployment and this effect is significant in all countries. The size of the effect of benefits, in terms of the expected unemployment duration, is higher in France and Germany relative to the UK. In particular, the expected unemployment duration for recipients is 16.75 months in France, 12.27 months in Germany, and 11.38 months in the UK.

Concerning the effect of UI benefits on employment stability, we find that an additional month in unemployment for those who exit unemployment receiving benefits increases employment stability. This positive correlation between previous unemployment and subsequent employment duration for the recipients is statistically significant for the short-term unemployed, i.e. those being unemployed for less than 12 months, in France and Germany. In terms of the expected employment duration, we find that receiving benefits during unemployment increases the time spent in subsequent employment by 6 months in France, by 9 
months in Germany, and by less than 1 month in the UK. The results indicate that in the countries with more generous benefits, recipients who search for a longer period within the first year in unemployment obtain higher employment stability.

The rest of the paper is organised as follows. Section 2 discusses the theoretical framework and the empirical evidence, while Section 3 describes the data and the institutional features of the countries in the study. The econometric model is presented in Section 4 and the results of the empirical analysis in Section 5. The conclusions of the study are drawn in Section 6 .

\section{Theoretical Arguments and Empirical Evidence}

The theoretical analysis for the effect of UI benefits on the escape rate out of unemployment predicts that higher benefits and longer benefit duration lead to longer unemployment spells. The standard framework of analysis is based on models of job search (e.g., Mortensen, 1977; Devine and Kiefer, 1991; Lippman and McCall, 1976). In these models, the representative worker is assumed to choose the optimal search strategy in order to maximise the present value of her lifetime utility which depends on income and leisure. Offers, which are draws from a stationary distribution arrive randomly one at each point in time and the worker has to choose sequentially whether to accept the current offer or to continue searching. The optimal strategy consists of the reservation wage and the optimal search effort. The reservation wage is such that the expected gain from rejecting an offer and continue searching is equal to the value of accepting the current wage offer. The search intensity is determined by the equality of the marginal cost and the marginal benefit of search. The exit rate from unemployment is defined as the product of the probability of receiving an offer times the 
probability of accepting it. The exit rate increases with search intensity because the arrival rate of job offers increases. The exit rate also rises as the reservation wage declines since the probability of an offer being accepted increases.

Under this framework, benefit recipients choose higher reservation wages and devote less search effort since the opportunity cost of search is lower. This leads to a drop in the exit rate from unemployment for recipients. Further results have shown that close to benefits exhaustion the unemployment exit rate increases (Mortensen, 1977; Meyer, 1990). The reason is that close to benefit termination the value of being unemployed drops, so the marginal benefit of search increases and the reservation wage falls leading to a higher exit rate.

This disincentive effect of the UIB system has been the conventional wisdom in modern labour economics. However, UI benefits can have an effect not only on the unemployment duration but also on the post-unemployment outcomes. There are two channels through which the effect of benefits on the subsequent employment has been illustrated.

The first, which has been discussed more in the literature, focuses on the effect of UI on the post-unemployment wages. As long as benefits lead to higher reservation wages, this should be reflected on the wages offered by the subsequent job. In an early study, Ehrenberg and Oaxaca (1976) found a positive effect of benefits on post-unemployment wages. More recently, Addison and Blackburn (2000) review the literature and provide results which suggest a weak effect.

The second channel, suggests that benefits can also have an effect on the subsequent employment duration by allowing the unemployed to accept job offers which are compatible with their skills and therefore less likely to dissolve. Marimon and Zilibotti (1999), 
developed an equilibrium search-matching model in which UIB has the standard effect of reducing employment, but also helps workers to get a suitable job. Following Burdett (1979), unemployment benefits provide a "search subsidy" for giving the unemployed the time to find not just a job, but the "right job". In particular, unemployed without benefits might accept unsuitable jobs. On the other hand, generous benefits can make the unemployed very selective and reject matches which would have been socially efficient.

Other theoretical arguments based on the implicit contract literature suggest that UIB can affect employment duration by inducing layoffs. The analysis is forward-looking in the sense that the future entitlement of benefits makes an optimal response of a firm, which faces demand fluctuations and firm specific human capital, to lay off workers with high level of UI entitlement and recall them back close to benefits exhaustion (Feldstein, 1976).

The empirical literature on the effect of UI on re-employment duration is rather limited mainly due to the scarcity of large micro data sets which provide information both on labour market histories and on UI benefits and has focused on Canadian and US data. Belzil (2001), studies the effect of the UI benefits on the exit rate from unemployment and subsequent employment using an inflow sample of unemployed from administrative files of the Canadian unemployment insurance program. He distinguishes between the "Matching" hypothesis and the "Adverse Selection" hypothesis. The first suggests that there is a positive correlation between the unemployment duration and subsequent job duration for benefit recipients, while the second refers to a spurious correlation between unemployment and subsequent job duration due to unobserved heterogeneity. His findings suggest that both hypothesis contribute to explain the observed correlation between unemployment duration and subsequent job duration. However, the effect of UI benefits is rather weak. In particular, 
he reports that increasing the maximum benefit duration by one week would raise expected unemployment duration by 1.0 to 1.5 days, but raise expected job duration by only 0.5 to 0.8 days.

Baker and Rea (1998), adopting the forward looking-approach, they examine whether the requirements that workers must satisfy to become eligible for benefits in the future affect employment duration. Employing Canadian data, they find a significant increase in the employment hazard in the week that an individual satisfies the eligibility requirement in many regions of the country. Jurajda (2002), looks also at the effect of future entitlement to UI benefits on the probability to exit employment using US data on labour market histories of displaced workers. Estimating a competing risk duration model he finds that being entitled to UI benefits significantly increases the layoff hazard. However, neither the length of potential UI entitlement nor the level of UI benefits affect the layoff hazard. Finally, the quit hazard is not affected by any of the UI system parameters.

\section{Data Description}

The analysis is based on individual data from the European Community Household Panel (ECHP, 1994-2001). The ECHP is a survey based on a standardised questionnaire that involves annual interviewing of a representative panel of households and individuals in each country, covering a wide range of topics including demographics, employment characteristics, education etc. In the first wave, a sample of some 60,500 nationally represented households - approximately 130,000 adults aged 16 years and over - were interviewed in the then 12 Member States. There are three characteristics that make the ECHP relevant for this study. 
That is, the simultaneous coverage of employment status, the standardized methodology and procedures yielding comparable information across countries and the longitudinal design in which information on the same set of households and persons is gathered. The countries studied are France, Germany, and the UK. We choose these countries because they provide different configuration of the labour market institutions. These differences mainly refer to the Employment Protection Legislation, which affects hiring and firing, and the Unemployment Insurance system.

Using the calendar of activities for the years 1994-2001, which provides monthly information about the labour market status in the previous year, we construct individual labour market histories up to December 2000. The sample consists of an inflow of male individuals in unemployment after the date of interview in year 1994 until December 1999. We restrict entry into unemployment before the end of 1999, so that there is information on the labour market history of at least one additional year following the entry into unemployment (up to the end of 2000). The analysis is focused on males because of their higher attachment to the labour market and we consider single spells of unemployment and subsequent employment.

Unemployment spells can end in one of the following two ways: by entering employment, or by exiting the labour force. Unemployment spells that last longer than the end of 1999 are treated as right censored. Transitions from unemployment to employment are considered as completed spells, while transitions from unemployment out of the labour force are considered as continued unemployment spells. The unemployed who exit the labour force can either become employed, re-enter unemployment, or remain out of the labour force. That is, the duration of unemployment for those who have been out of the labour force is the sum of the duration of the first unemployment spell and the duration of the spell out of the labour 
force.

Transitions in the sample are depicted in Table (1). The first panel shows that out of the 1664 total number of unemployment spells in all countries, 66.17 per cent (1101 spells) terminated with a transition to a job, while 7.93 per cent (132 spells) were right censored. The remaining 25.90 per cent (431 spells) exited the labour force after the first unemployment spell. From the 431 spells who exit the labour force, 22.74 per cent (98 spells) entered employment after a remaining for some time out of the labour force, 33.41 per cent (144 spells) are right censored since they remained out of the labour force until the end of the observation period, while the remaining 43.85 per cent (189) re-entered unemployment. These last spells are treated as right-censored unemployment spells. That is, the majority of the individuals who reported that they exit the labour force after the initial spell of unemployment, either re-entered unemployment or obtained a job. The rest of Table (1) includes the transitions separately for each of the three countries in the study showing a similar pattern.

\subsection{Description of Data on Unemployment Insurance}

\subsubsection{Benefit Indicator}

Information on unemployment benefits in the ECHP is rather limited and is based on two main sources. The first, refers to the question of whether an unemployed receives benefits at the time of the interview. The second, refers the amount of benefits received during the year. We need to combine both these sources to determine whether an unemployed receives benefits during a spell. This is particularly relevant for short spells. Relying only on whether 
Figure 1: Types of unemployment spells

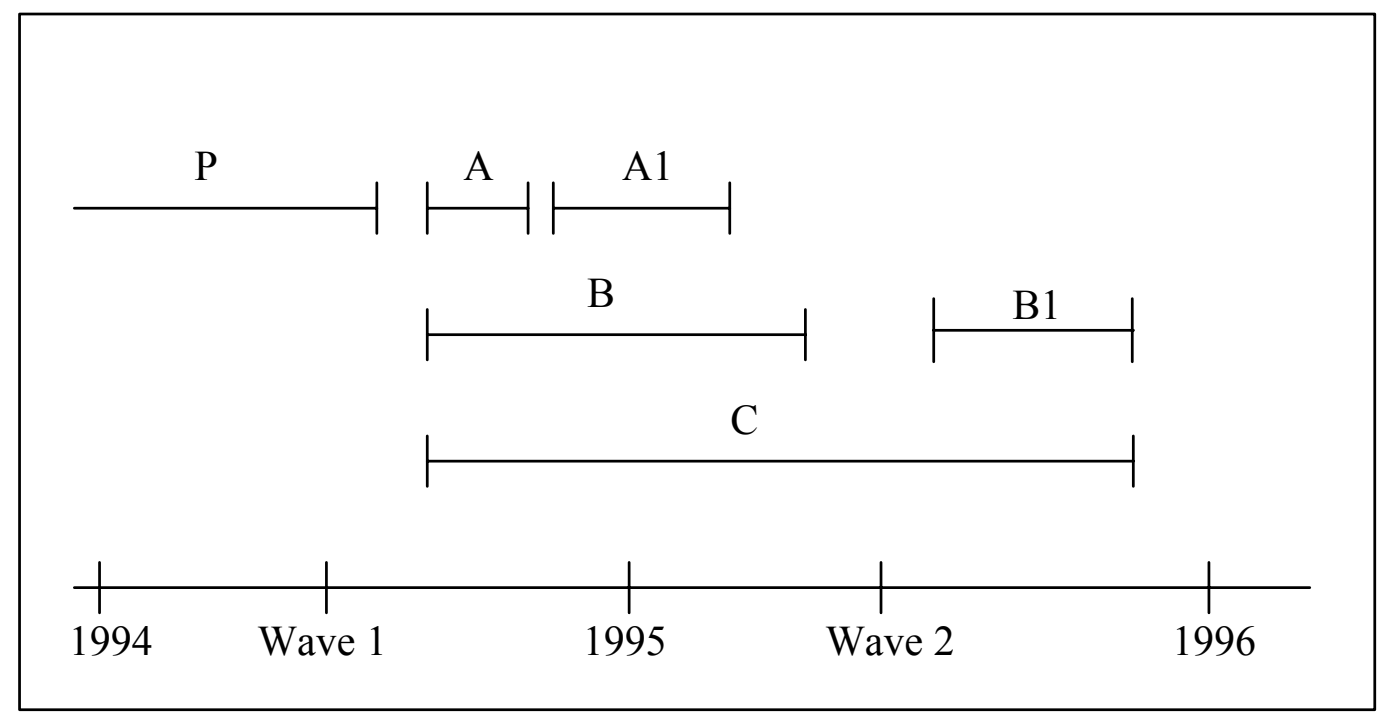

an unemployed receives benefits at the time of the interview can be uninformative for short spells given that they might not coincide with the time of any interview.

For instance, for spells of type C in Figure (1) which are long enough to reach the time of the next interview, the information on receipt of benefits at the time of the next interview is used. However, this source of information is not sufficient to distinguish recipients vs. non recipients for spells like A or B in Figure (1). For these spells, the information on the amount of benefits received during the year in which the spell has started is used. That is, a positive amount of benefits is associated with the receipt of benefits.

The need to rely on the information for the amount of benefits received during a year to identify receipt of benefits, creates some difficulties in the case an individual experiences two unemployment spell within in a year. The reason is that it is not immediately clear whether the amount of benefits received refers to the first, to the second, or to both spells. Notice that the spells in the sample start after the first interview in 1994 (Spells A, B or C). 
However, an individual could be unemployed twice in the year in which the first spell starts, if another spell has started before the 1994 interview (Spell P), or if the individual re-enters unemployment after the first spell in the same year (Spells A and A1, or B and B1).

For those who experience another unemployment spell (Spell P) before entering unemployment and receive benefits during the year of entry, both sources of information on benefits are used to infer the benefit status. That is, if the spell is long enough so that it reaches the month of the following interview (Spell C), the dummy for receiving benefits at the time of the interview at the next wave is used. If the spell is not long enough to reach the next interview, but it reaches the following year (Spell B), then the amount of benefits received in the following year is used to infer whether the unemployed received benefits during this spell. Inference for spells of type $\mathrm{A}$ is not possible when another spell $\mathrm{P}$ exists and the unemployed receives benefits during that year. Another type of spells for which we cannot infer the benefits status are spells followed by another spell in the same year. This is shown in Figure (1) as a combination of spells B and B1. If the individual receives benefits in both years then it is not possible to associate them with one of the two spells. Notice that in this case no spell coincides with a month in which the individual has been interviewed. The same holds for the combination of spells A and A1.

Therefore, it is possible to identify recipients and non-recipients, except for cases in which the unemployment spell is very short and does not coincide with any month of an interview, the individual experiences another spell, and receives benefits in the same year. These cases are dropped from the analysis. ${ }^{5}$ Although these cases are few relative to the initial sample,

\footnotetext{
${ }^{5}$ For France, the initial inflow sample consists of 635 spells from which 90 have missing benefit indicator. For Germany, the initial sample is 914 spells with 88 missing the benefit indicator, while for the UK the initial sample is 464 with 43 missing benefits.
} 
it is likely that they create some selection bias since they tend to consist of spells with short unemployment duration. In the next section, we describe a procedure that is used to correct for this possible selection bias by giving additional weight to the spells in the sample with unemployment duration equal to the duration of the spells dropped.

\subsubsection{Benefit Duration}

Regarding the duration of benefits, the ECHP does not include any such information. However, we can construct a measure of benefits duration using the two sources of information on benefits used so far and the unemployment duration. ${ }^{6}$ This constructed benefit duration variable coincides with the unemployment duration for those who have not exhausted their benefits before leaving unemployment. That is, the duration of benefits is censored although this censoring is of a different kind compared to the censoring of the unemployment duration. Combining the information on the receipt of benefits with the amount of benefits we can identify those who have exhausted their benefits.

To see this, consider the spell of type C in Figure (1). If the unemployed does not receive benefits at the time of the next interview but has received benefits during the year in which entered unemployment, then is considered as a benefit recipient who has exhausted benefits at the end of 1994. Similarly, if an unemployed with a spell of type B receives benefits in 1994, but not in 1995, then is considered as if the benefits were exhausted at the end of 1994. For long spells, a comparison of the benefit receipt indicator at the different waves provides information on benefits exhaustion. That is, if an unemployed receives benefits at the interview in wave 2 , but does not receive any more benefits at the interview in wave 3 , it

\footnotetext{
${ }^{6}$ Bover, Arellano, and Bentolila (2002) use data with similar features.
} 
is assumed given that is still unemployed that has exhausted the benefits at the end of 1995 . Finally, for short spells of type A the benefit duration coincides with the unemployment duration.

Therefore, the data are asymmetric in the two durations and a monthly benefit indicator variable $I\left(t_{b} \geq t_{u}\right)$ is constructed, which is equal to 1 if $t_{b} \geq t_{u}$, that is, if unemployed still receive benefits, where $t_{b}$ refers to the duration of benefits and $t_{u}$ to the duration of unemployment.

\subsection{Descriptive Statistics}

The explanatory variables used in the analysis, apart from the benefits indicator, include age, education, the labour market status of the spouse (for those having a spouse), job type (if an unemployed person enters employment), and year dummies. In France and Germany, as Table (2) shows, around 75 per cent of the unemployed have finished secondary or less than secondary education, while in the UK, 50 per cent of the individuals have finished higher education. Table (2), shows also that the unemployed are younger in France. The share of the unemployed in the sample receiving benefits is 45 per cent for France, 66 per cent for Germany, and 30 per cent for the UK. It is the feature of our data that provides this variation in the receipt of benefits since we are drawing an inflow sample into unemployment from a representative survey of the population. It is usually in administrative data the case in which non-recipients is a minority with certain characteristics, such as seasonal workers. Nevertheless, it is expected that receipt of benefits is associated with certain individual 
characteristics some of which are observed, while others are unobserved. ${ }^{7}$ As Table (3) reports, benefit recipients are less educated than non-recipients, and they are older. Also, recipients are more likely to be married relative to non-recipients.

\subsubsection{Empirical Hazards}

Empirical unemployment hazards by benefits for each country are shown in Figure (2). The empirical hazard is given by the proportion of the individuals who are still unemployed at time $t$ and exit unemployment at time $t$. We distinguish between unemployed with and without benefits. The latter include those unemployed who have never received benefits and those who have received benefits during the unemployment spell, but for a shorter period than the duration of the spell. For all the countries, non-recipients face higher hazard rates from unemployment during the initial part of the spell. The decreasing hazard rate observed could be either due to duration dependence, or due to individual characteristics affecting the exit rate from unemployment. Individuals with characteristics which affect positively the exit rate will leave first, so the drop in the empirical hazard could be due to the remaining individuals having characteristics which do not favour exiting from unemployment. The econometric analysis in the next section tries to distinguish these effects.

Figures (3), presents the empirical employment hazard by benefits for each country. The baseline hazard follows the same pattern between recipients and non-recipients in each country. During the first months of the employment spell, individuals who were receiving benefits at the time of their exit from the preceding unemployment spell have lower exit rates. There is a spike of the hazard from employment around the first 12 months which

\footnotetext{
${ }^{7}$ In the econometric model in the next section we describe how to control both for observed and unobserved characteristics in the framework of duration analysis.
} 
must be related to the fixed term contracts, while afterwards the hazard falls with duration.

\subsection{The Unemployment Insurance System}

The key features of the unemployment insurance benefit system are the amount and the duration of benefits. There is a distinction between Unemployment Insurance (UI) and Unemployment Assistance (UA). When an individual is either not eligible or no longer eligible for UI, he or she may seek UA benefits. UK has the lowest replacement ratios of UI, as can be seen in Table (4). The unemployment benefit in the UK is a flat rate covering 30 per cent of the average wage. Payment of UA is flat in France and the UK, and 53 per cent of previous wage in Germany, while in all countries UA is means-tested. Eligibility conditions for both UI and UA vary across these countries in terms of the length of previous employment. For France, unemployed are eligible for benefits conditional they have been employed for 4 months in the last 8 months, while for Germany, the condition is 360 days in the last 3 years.

Duration for UI varies by employment record and/or by age in France and Germany, as can be seen in Table (5). France has the highest UI benefit duration (up to 60 months). Duration of UA is indefinite in France, Germany and the UK. This institutional information indicates that the UI system in France and Germany is more generous relative to the UK, both in terms of the level and the duration of benefits. 


\section{Econometric Model}

To estimate the effect of unemployment benefits on unemployment and subsequent employment, both transitions are modeled. Each transition is assumed to follow the proportional hazard $(\mathrm{PH})$ specification with a flexible baseline hazard. Individual differences in the hazard rate of unemployment are explained by the observed characteristics $X$, the elapsed duration itself $t_{u}$, and a time-varying dummy variable $I\left(t_{b} \geq t_{u}\right)$, which indicates whether an individual receives benefits in each month during the unemployment spell.

For no recipients $\left(t_{b}=0\right)$ and for those who have exhausted their benefits $\left(t_{b}<t_{u}\right)$, the indicator variable $I\left(t_{b} \geq t_{u}\right)$ is zero. For those who still receive benefits $\left(t_{b} \geq t_{u}\right)$, it takes the value of one. The effect on the hazard for those still with benefits is assumed to be the same independent of the actual benefit duration. This assumption is made since we cannot condition on the whole path of benefits duration, as it is not observed. That is, $I\left(t_{b} \geq t_{u}\right)$ is predetermined and not strictly exogenous. ${ }^{8}$

Differences in the hazard rate out of employment are explained by the observed characteristics $X$, the elapsed employment duration $t_{e}$, the completed unemployment duration $\tau_{u}$, and an interaction of an indicator of benefit receipt during the transition from unemployment to employment $b_{u}$, with unemployment duration.

We start from the simple case in which each transition is estimated separately assuming independence between the two processes. That is, conditional on observed characteristics, the process by which unemployed become employed is independent of the process by which they exit the subsequent employment.

\footnotetext{
${ }^{8}$ Bover, Arellano, and Bentolila (2002), provide a detailed discussion on this issue.
} 
The transition rate from unemployment to employment at time $t$, conditional on $X$, and $I\left(t_{b} \geq t_{u}\right)$, can be specified as:

$$
\theta_{u e}\left(t \mid x, t_{b}\right)=\lambda_{u e}(t) \cdot \exp \left(X^{\prime} \beta_{u e}+\delta \cdot I\left(t_{b} \geq t_{u}\right)\right)
$$

while the transition rate from a job at $t$ conditional on $X$, the previous unemployment duration $\tau_{u}$, and the interaction term between the benefit indicator and unemployment duration, is specified as:

$$
\theta_{e}(t)=\lambda_{e}\left(t \mid x, b_{u}\right) \cdot \exp \left(X^{\prime} \beta_{e}+\gamma_{1} \tau_{u}+\gamma_{2}\left(b_{u} \cdot \tau_{u}\right)\right)
$$

The functions $\lambda_{j}(t)$, with $j=u e, e$, represent individual duration dependence. The effect of benefits on the transition rate to employment is measured by $\delta$. The effect of previous unemployment duration for non-recipients on the transition rate out of employment is captured by $\gamma_{1}$, while $\gamma_{2}$ captures the difference of the effect of previous unemployment duration on the employment hazard between recipients and non-recipients. Finally, $\beta_{j}$ measures the effect of the characteristics in the vector $X$.

The baseline hazard has a semi-parametric representation using a piece-wise constant function with monthly intervals:

$$
\lambda_{j}(t)=\exp \left(\sum_{k}\left(\lambda_{j, k} I_{k}(t)\right)\right.
$$

where the subscript $k=(1,2,3 \ldots)$ denotes the monthly intervals and $I_{k}(t)$ are time-varying dummy variables which are one in subsequent monthly intervals. Since there is a constant included in $X$, the normalisation $\lambda_{j, 1}=0$ is used. 
The conditional density functions of the completed unemployment duration $\tau_{u}$ and the completed employment duration $\tau_{e}$ can be written as:

$$
\begin{gathered}
f_{u e}\left(\tau_{u} \mid x, t_{b}\right)=\theta_{u e}\left(\tau_{u} \mid .\right) \cdot \exp \left(-\int_{0}^{\tau_{u}} \theta_{u e}(s \mid .) d s\right) \\
f_{e}\left(\tau_{e} \mid x, b_{u}\right)=\theta_{e}\left(\tau_{e} \mid .\right) \cdot \exp \left(-\int_{0}^{\tau_{e}} \theta_{e}(s \mid .) d s\right)
\end{gathered}
$$

Assuming for the moment that the two processes are independent we can write the likelihood function as follows:

$$
L_{j}=\prod_{t=1}^{N}\left[f_{j}\left(\tau_{j}\right)\right]^{c_{j}} \cdot \prod_{t=1}^{N}\left[S_{j}\left(\tau_{j}\right)\right]^{1-c_{j}}
$$

where $S_{j}\left(\tau_{j}\right)=1-F_{j}\left(\tau_{j}\right)$ is the survivor function, and $c_{j}$ is a dummy variable which takes the value of 1 if the spell $j$ is completed and the value of zero if the spell is censored.

The model is also estimated allowing for unobserved heterogeneity to affect the transitions from the two states:

$$
\begin{aligned}
& \theta_{u e}\left(t \mid x, \varepsilon_{u e}, t_{b}\right)=\lambda_{u e}(t) \cdot \exp \left(X^{\prime} \beta_{u e}+\delta \cdot I\left(t_{b} \geq t_{u}\right)+\varepsilon_{u e}\right) \\
& \theta_{e}\left(t \mid x, \varepsilon_{e}, b_{u}\right)=\lambda_{e}(t) \cdot \exp \left(X^{\prime} \beta_{e}+\gamma_{1} \tau_{u}+\gamma_{2}\left(b_{u} \cdot \tau_{u}\right)+\varepsilon_{e}\right)
\end{aligned}
$$

The unobserved heterogeneity is modeled as a random variable $\varepsilon_{j}$, which follows a discrete distribution with two points of support, with probabilities $p_{j}$ and $1-p_{j}$. Assuming independence between the unobserved terms in the two processes the conditional likelihood functions are similar to those in (6). 
So far, we assumed that the two processes were independent conditional on the observed characteristics. If, for instance, unobserved characteristics have a negative effect on the probability of the unemployed to find a job and a positive effect on the transition out of employment, this could result in the finding that longer unemployment durations imply shorter subsequent job durations. To account for this spurious state dependence between unemployment and job duration, the model is estimated jointly allowing the unobserved heterogeneity components to be correlated.

Defining $G\left(\varepsilon_{u e}, \varepsilon_{e}\right)$ as the joint distribution of the unobserved characteristics $\varepsilon_{u e}$ and $\varepsilon_{e}$, the joint density function of $\tau_{u}$ and $\tau_{e}$ conditional on $X$ equals:

$$
f_{u e, e}\left(\tau_{u}, \tau_{e} \mid x, \varepsilon_{u e}, \varepsilon_{e}, b_{u}, t_{b}\right)=\int_{\varepsilon_{u e}} \int_{\varepsilon_{e}} f_{u e}\left(\tau_{u} \mid x, \varepsilon_{u e}, t_{b}\right) f_{e}\left(\tau_{e} \mid x, \varepsilon_{e}, b_{u}\right) d G\left(\varepsilon_{u e}, \varepsilon_{e}\right)
$$

The case where $\varepsilon_{u e}$ and $\varepsilon_{e}$ follow a bi-variate discrete distribution with two point of support is considered. ${ }^{9}$ Therefore, $G$ is a discrete distribution of unobserved heterogeneity with 4 points of support and three free probabilities as follows: $\operatorname{Pr}\left(\varepsilon_{u e}=\varepsilon_{u e}^{1}, \varepsilon_{e}=\varepsilon_{e}^{1}\right)=p_{1}$, $\operatorname{Pr}\left(\varepsilon_{u e}=\varepsilon_{u e}^{1}, \varepsilon_{e}=\varepsilon_{e}^{2}\right)=p_{2}, \operatorname{Pr}\left(\varepsilon_{u e}=\varepsilon_{u e}^{2}, \varepsilon_{e}=\varepsilon_{e}^{1}\right)=p_{3}, \operatorname{Pr}\left(\varepsilon_{u e}=\varepsilon_{u e}^{2}, \varepsilon_{e}=\varepsilon_{e}^{2}\right)=p_{4}$, where $0 \leq p_{i} \leq 1$, and $\sum_{i} p_{i}=0, i=1,2,3,4$.

The likelihood function to be maximised is the average of (6), using the joint density function in (9), over all possible combinations of unobserved heterogeneity.

$$
L=\sum_{p_{i}} L_{u e, e}=\sum_{p_{i}}\left(\prod_{t=1}^{N}\left[f_{u e, e}\left(\tau_{u}, \tau_{e}\right)\right]^{c_{j}} \cdot \prod_{t=1}^{N}\left[S_{u e, e}\left(\tau_{u}, \tau_{e}\right)\right]^{1-c_{j}}\right)
$$

\footnotetext{
${ }^{9}$ Van de Berg (2000), provides a review of the Mixed Proportional Hazard Model (MPH).
} 


\subsection{Sample Selection Bias}

In Section 3, we discussed that due to the limited information about the benefits, we had to drop some unemployment spells for which we did not know whether the individual was receiving benefits or not. These spells tend to be short unemployment spells which could create some selection bias in the estimated results. To correct for this, we construct weights for those unemployment spells in our sample which have the same duration as the spells for which we do not observe the benefit indicator. For instance, the weight for those with

$x$ months of unemployment duration is $\frac{n_{b}^{x}+n_{n b}^{x}}{n_{b}^{x}}$, where $n_{b}^{x}$ denotes the number of spells with duration $x$ for which we observe the benefits indicator, while $n_{n b}^{x}$ denotes the number of spells with duration $x$ for which we do not observe the benefit indicator and we drop from the sample. It is obvious that spells with durations for which we always observe the benefit indicator, thus $n_{n b}^{x}=0$, the weight is equal to 1 . The estimation of the econometric model, taking into account these weights, requires just to multiply the contribution of each spell in the likelihood by the corresponding weight.

\section{Empirical Results}

We start from the simple case in which each transition is estimated separately assuming independence between the two processes. We first present the estimates of the transitions out of unemployment. From Table (6), being more than 50 years old in France and Germany lowers the exit rate from unemployment. For the UK, age does not have an effect except for the young age group, between 20-25 years old, who have a higher exit rate compared to the older group. Being more educated in Germany and the UK shifts up the hazard 
to employment, while for France, unemployed with higher education have lower exit rates but the effect is significant only at the 10 per cent significant level. Having a spouse who is employed increases the transition rate to employment in all countries. If the spouse is unemployed the effect on the hazard rate is positive for France and Germany, but negative for the unemployed men in the UK. Finally, the receipt of unemployment benefits reduces the hazard of leaving unemployment. This result is in line with the theoretical discussion in Section 2 and confirms the previous empirical findings in the literature.

Duration dependence is captured in a flexible way by using additive dummies for each monthly duration. Thus, the variable Durt in Table (6) is equal to 1 if the hazard corresponds to a duration of unemployment of $t$ months. Table (6), presents the coefficients of the duration dummies up to month 24 , the time at which duration is censored because of the small number of observations with duration of more than 24 months. The coefficients in Table (6) indicate a non-monotonic duration dependence. After the first six months, in France and the UK, there exists negative duration dependence. For Germany, duration dependence is significant only at longer duration.

The results for the transition out of employment are presented in Table (7). As discussed in the previous section, the specification includes the duration of the previous unemployment spell and an interaction term of the previous unemployment duration with the benefits indicator. An additional month of being unemployed has a positive effect on the exit rate from subsequent employment, but the effect is not significantly different from zero. From the interaction term of previous unemployment duration with the benefits indicator we obtain that an additional month of unemployment lowers the exit rate out of the subsequent employment for the recipients. That is, for the recipients, longer unemployment duration 
leads to longer employment duration. This effect appears significant only in Germany at the 5 per cent level.

In Table (8), we estimate the transition out of employment allowing for the effect of previous unemployment duration to differ depending on whether the individual was short, medium, or long-term unemployed. We do so by distinguishing the unemployment spells to those which lasted less than 6 months, between 6-12 months, 12-24 months, and those more than 24 months. Interacting these sub-groups with the unemployment duration we can obtain the effect of an additional month of unemployment duration for each of the subgroups. The intuition is that an additional month of being unemployed may have a different effect for short-term compared to long-term unemployed. Table (8), shows that an additional month of unemployment duration lowers the hazard from subsequent employment for those who have been unemployed for less than 6 months in France, and between 6-12 months in Germany. The effect in both cases is significant at the 5 per cent significance level. These results show that receiving unemployment benefits while unemployed, which allows for a longer searching period, increases employment stability provided that the unemployment spell is short.

For the other controls, we obtain that age does not affect the transition out of employment in France and the UK. In Germany, workers less than 50 years old have a lower hazard from employment. Higher education for Germany, and second level of secondary education for France, lower the hazard from employment indicating an effect of skills on employment stability. Having a spouse and the number of kids does not appear to affect the transition out of employment. Being in a paid employment (full, or part time) compared to be self-employed increases the hazard from employment. Finally, in a similar way as for the unemployment 
transition, we specify duration dependence flexibly with additive dummies. These dummies in Table (8) indicate a non-monotonic duration dependence. For Germany, the baseline hazard is increasing around the first year and is decreasing thereafter. For France and the UK, there exists negative duration dependence after the first 6 months of employment.

\subsection{Unobserved Heterogeneity and Robustness}

Both models have been estimated allowing for unobserved heterogeneity. As discussed in the previous section, the unobserved component is assumed to follow a discrete distribution with two points of support. In all cases, allowing for a shift in the baseline hazard due to some unobserved characteristics was rejected. ${ }^{10}$ Estimating jointly the two transitions and allowing for the unobserved components of each transition to be correlated led to the same result. $^{11}$

Using different distributional assumptions about the determinants of the hazard function allows to check the sensitivity of the results based on these assumptions. Using the log-logistic distribution for the duration dependence and the gamma distribution for the unobserved component, we find the coefficient of the unobserved heterogeneity to be significant. However, allowing for flexible duration dependence, the unobserved heterogeneity coefficient is not any longer significant. Therefore, the flexible duration dependence is preferred since assuming a functional form for duration dependence does not capture correctly the shape of the actual hazard function, which is then captured by the unobserved component. Therefore, when

\footnotetext{
${ }^{10} \mathrm{~A}$ grid search has been implemented choosing different initial values for the second point of support and assigning different probabilities without any improvement in the log-likelihood.

${ }^{11}$ In the presence of unobserved heterogeneity, the benefit indicator becomes endogenous as discussed in Bover et.al., (2002). In that case, a separate hazard and heterogeneity term for benefit duration should be specified which is allowed to be correlated with the heterogeneity term of unemployment duration.
} 
both transitions are estimated using flexible duration dependence, we conclude that there is no unobserved heterogeneity left. ${ }^{12}$

\subsection{Predicted Hazard Rates}

In Figure (4), we present the predicted unemployment hazard rates computed from our model. Figure (4), refers to individuals who are 50-60 years old, low educated, single with no kids, in year 1996. We present the hazard rate across the unemployment duration grouped in short (less than 6 months), medium (6 to 12 months), long (12 to 24), and very long (above 2 years), both for recipients and non-recipients. We see that unemployed without benefits face a higher exit rate from unemployment compared to those with benefits in all countries.

Figure (5), presents the predicted hazard rates out of employment across different duration of previous unemployment, by benefits and by country. The graphs on the left part of Figure (5) show the predicted employment hazard by previous unemployment duration for short-term unemployed. An additional month of previous unemployment increases the employment hazard for non-recipients in all countries. For the recipients in France, there is a decline of the employment hazard rate for each additional month of unemployment, while for the recipients in Germany and the UK, there is an increase but lower than the one for the non-recipients. This creates a difference on the employment hazard between recipients and non-recipients as a function of previous unemployment duration.

The graphs on the right part of Figure (5) refer to the medium term unemployed. In Germany, we observe that the difference in the employment hazard rates between recipients and non-recipients increases with an additional month of previous unemployment conditional

\footnotetext{
${ }^{12}$ The results from these estimations are not reported and are available upon request.
} 
on having been unemployed between 6-12 months. For France and the UK, this difference remains the same.

\subsection{Expected Durations}

The results obtained from the econometric analysis indicate that benefits reduce the exit rate from unemployment, but they also decrease the exit from the subsequent employment. To obtain a measure of these effects we present, in Table (9), the expected duration of unemployment and subsequent employment for a reference person by benefits. ${ }^{13}$ Panel A, shows that the expected unemployment duration for recipients varies from 16.75 months in France, to 12.27 months in Germany, and to 11.38 months in the UK. The effect is larger for France and Germany compared to the UK, which reflects the differences in the generosity of the UI system. The corresponding expected unemployment duration for non-recipients is 8.24 in France, 6.49 in Germany, and 7.54 in the UK, which is about half the one of the recipients in France and Germany, and about 60 per cent lower for the recipients in the UK.

In Panel B, we present the expected duration of employment evaluated at the expected duration of unemployment for each group. For instance, the expected employment duration for non-recipients refers to the reference person who did not receive benefits during the previous unemployment spell and whose unemployment spell length was equal to the expected unemployment duration of non-recipients. The expected employment duration for benefit recipients is 43.71 months for France, and 34.84 months for Germany. This is higher compared to non-recipients whose expected employment duration is 37.43 for France, and 25.47

\footnotetext{
${ }^{13}$ The reference person has finished secondary education, is 30-39 years old, single with no kids, with a regular job when employed, in 1996.
} 
for Germany. For the UK, the expected employment duration for both groups is very similar, 36.53 for non-recipients and 37.20 for recipients. That is, recipients remain in employment around 6 months longer than non-recipients in France, and around 9 months in Germany. The difference for the UK is less than a month. In other words, abolishing unemployment benefits for every individual in unemployment would reduce subsequent employment duration in France and Germany, while it would have no effect for the UK. These results indicate that individuals who receive benefits in countries with more generous UI system experience longer unemployment duration but also better employment stability.

\section{Conclusions}

In this paper, we provided an empirical assessment for the effect of UI benefits on unemployment duration and on the labour market adjustments following unemployment. In particular, we addressed the hypothesis that if benefits provide the unemployed with the necessary time to obtain a good match, then this would imply a positive correlation between unemployment and subsequent employment duration for the recipients. We identified the effect of UI benefits on employment duration by comparing the effect of previous unemployment duration between recipients and non-recipients. The econometric analysis was based on a two-state mixed proportional hazard model allowing for flexible duration dependence and state specific unobserved heterogeneity. The data come from the ECHP using 8 waves from 1994-2001, for France, Germany, and the UK.

The results are in accordance with the empirical literature on the effect of UIB on unemployment duration. In particular, we have found that the hazard rate out of unemployment 
is significantly lower for benefit recipients compared to non-recipients in all the three countries. The size of the effect of benefits, in terms of the expected unemployment duration, is higher in France and Germany relative to the UK. In particular, the expected unemployment duration for recipients is 16.75 months in France, 12.27 months in Germany, and 11.38 months in the UK.

Concerning the relation between unemployment and subsequent employment duration, we have found that an additional month in unemployment lowers the hazard from the subsequent employment for those still receiving benefits at the exit from unemployment, compared to those who do not receive benefits. This effect is significant for the recipients who have been short-term unemployed in France and medium-term unemployed in Germany. Thus, recipients who are searching for a longer period while unemployed obtain more stability in their subsequent employment, provided that they do not remain unemployed for too long. In terms of the expected employment duration, we found that receiving benefits during unemployment increases the time spent in employment by 6 months for France, by 9 months in Germany, and by less than 1 month in the UK.

These results indicate that generous unemployment insurance in terms of the level and duration of benefits, such as in France and Germany, improve the efficiency of the matching process since they increase employment stability. This can be the case because recipients are not forced to accept the first available offer. However, our results show that this effect arises as long as the time spent in unemployment is not too long. For the long term unemployed, signalling, or getting closer to the time that benefits elapse might have an effect on the conditions under which they accept a job offer or the type of employment. Our conclusion is that in order to achieve increased efficiency in the matching process, a combination of 
policy measures which improve the efficiency of the searching process for the unemployed, and adequate compensation which provides them with security, is required.

\section{References}

[1] Addison J. T. and Blackburn, M. L., (2000). 'The effects of unemployment insurance on postunemployment earnings', Labour Economics, vol. 7, pp. 21-53.

[2] Atkinson, A. and Micklewright, J., (1991). 'Unemployment compensation and labor market transitions: a critical review', Journal of Economic Literature, vol. 29, pp. 1679727.

[3] Baker, M. and Rea, S. A., (1998). 'Employment spells and unemployment insurance eligibility requirements', Review of Economics and Statistics, vol. 80, pp. 80-94.

[4] Belzil, C. (2001). 'Unemployment insurance and subsequent job duration: job matching vs. unobserved heterogeneity', Journal of Applied Econometrics, vol. 16(5), pp. 619-36.

[5] Bover, O., Arellano, M. and Bentolila, S. (2002). 'Unemployment duration, benefit duration and the business cycle', Economic Journal, vol. 112, pp. 223-65.

[6] Burdett, K. (1979). 'Unemployment insurance payments as a search subsidy: a theoretical analysis', Economic Inquiry, vol. 42, pp. 333-43.

[7] Devine, J. and Kiefer, N. (1991). 'Empirical Labor Economics', Oxford University Press, Oxford. 
[8] Ehrenberg, R.G., and Oaxaca, R.L. (1976). 'Unemployment insurance, duration of unemployment, and subsequent wage gain', American Economic Review, vol. 66(5), pp. $754-66$.

[9] Feldstein, M. S. (1976). 'Temporary layoffs in the theory of unemployment', Journal of Political Economy, vol. 84, pp. 837-57.

[10] Ham, J. C. and Rea, S. A. (1987). 'Unemployment insurance and male unemployment duration in Canada', Journal of Labor Economics, vol. 5, pp. 325-53.

[11] Heckman, J. and Singer, B. (1984). 'A method for minimizing the distributional assumptions in econometric models for duration data', Econometrica, vol. 52, pp. 271-320.

[12] Jurajda, S. (2002). 'Estimating the effect of unemployment insurance compensation on the labor market histories of displaced workers', Journal of Econometrics, vol. 108. pp. $227-52$.

[13] Lippman, S.A., and McCall, J.J. (1979). 'Studies in the Economics of Search', NorthHolland.

[14] Marimon, R. and Zilibotti, F. (1999). 'Unemployment vs. mismatch of talents: reconsidering unemployment benefits', Economic Journal, vol. 109, pp. 266-91.

[15] Meyer, B. (1990). 'Unemployment insurance and unemployment spells', Econometrica, vol. 58 , pp. $757-82$.

[16] Mortensen, D. (1977). 'Unemployment insurance and job search decisions', Industrial and Labor Relations Review, vol. 30, pp. 505-17. 
[17] Nickell, S.J and Layard, R. (1999). 'Labor Market Institutions and Economic Performance', in: Ashenfelter, O. and Card, D., Handbook of Labor Economics, Amsterdam, North-Holland, vol. 3, pp. 3029-84.

[18] OECD (1996). 'Employment Outlook'.

[19] OECD (1998). 'Benefits Systems and Work Incentives'.

[20] OECD (2002). 'Benefits and Wages'.

[21] Van de Berg, G. J. (2000). 'Duration Models: Specification, Identification, and Multiple Durations', in: Heckman, J. and Leamer, E., (eds.), Handbook of Econometrics, Vol. V, North-Holland.

[22] Wooldridge, J.M. (2002). 'Econometric Analysis of Cross Section and Panel Data', MIT Press. 

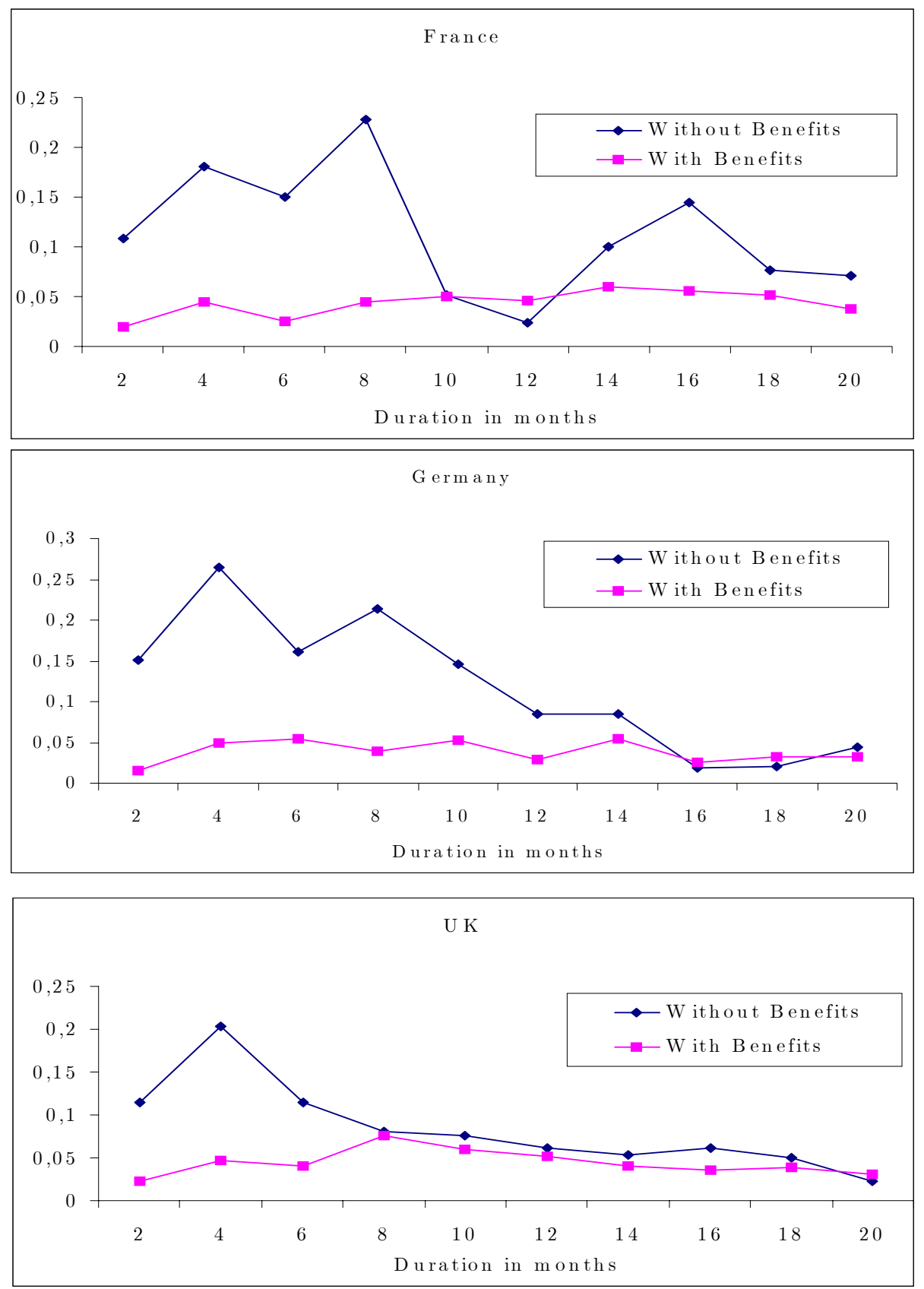

Figure 2: Empirical Unemployment Hazard by Country 

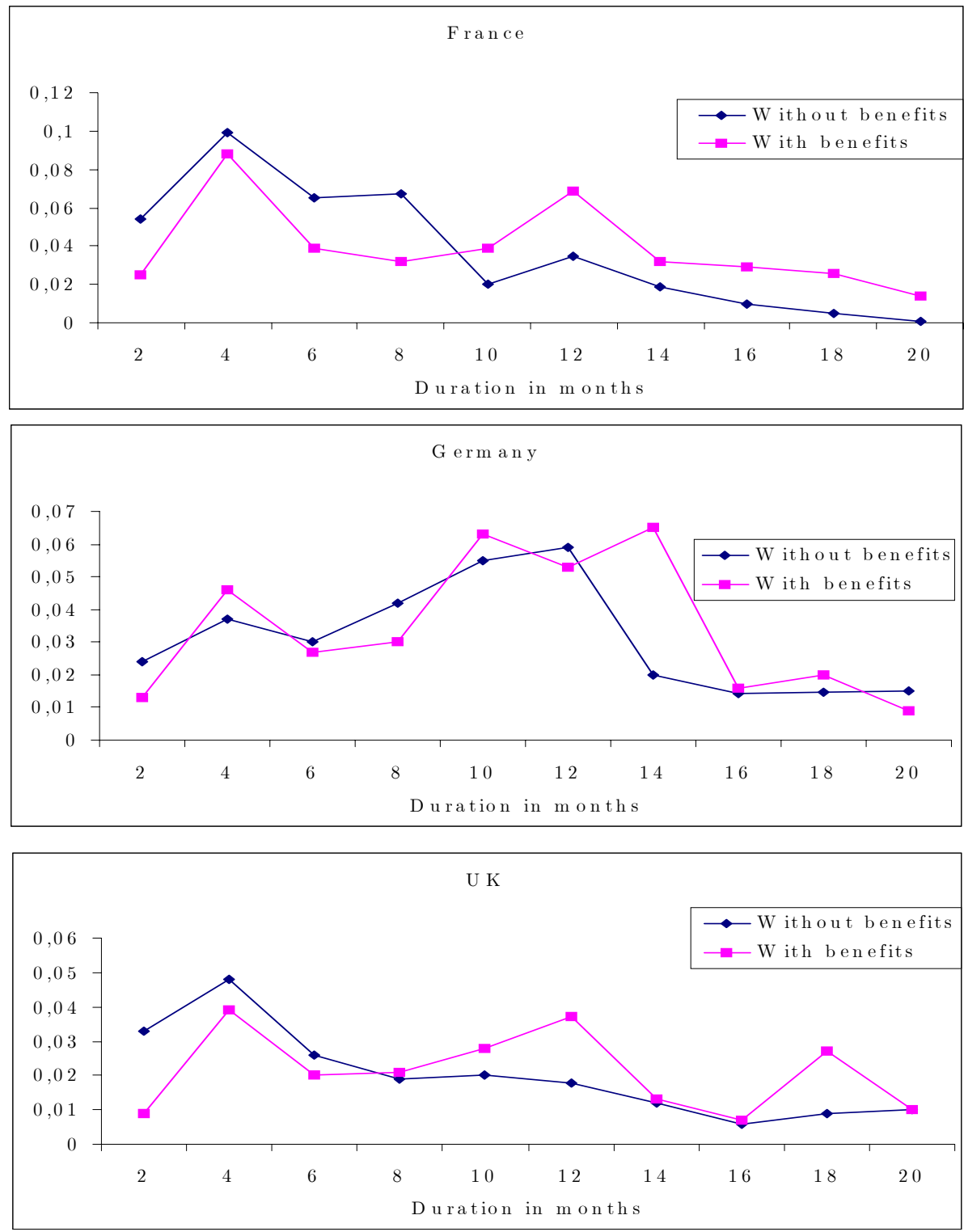

Figure 3: Empirical Employment Hazard by Country 

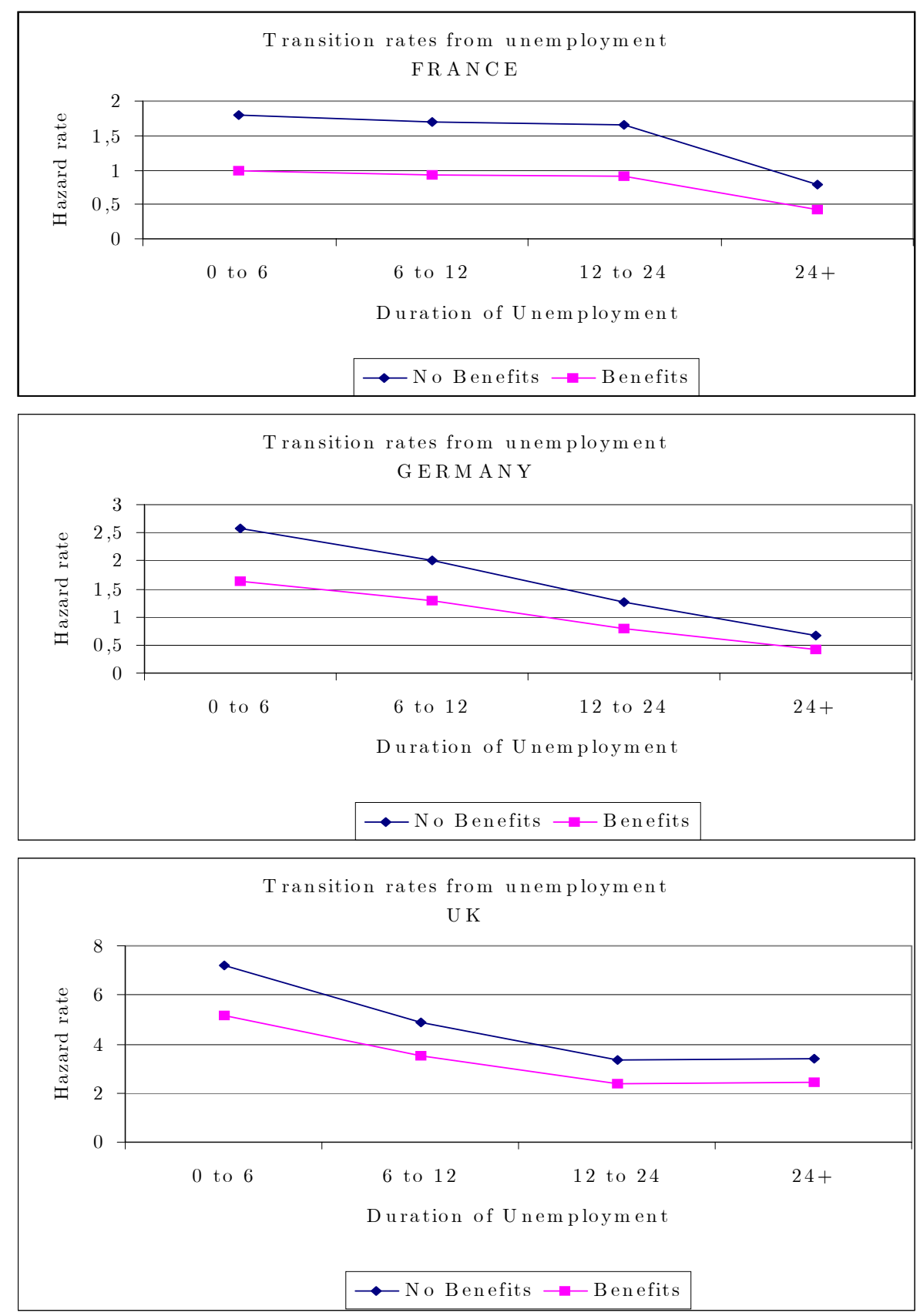

Figure 4: Estimated unemployment hazard rates by country and benefits 

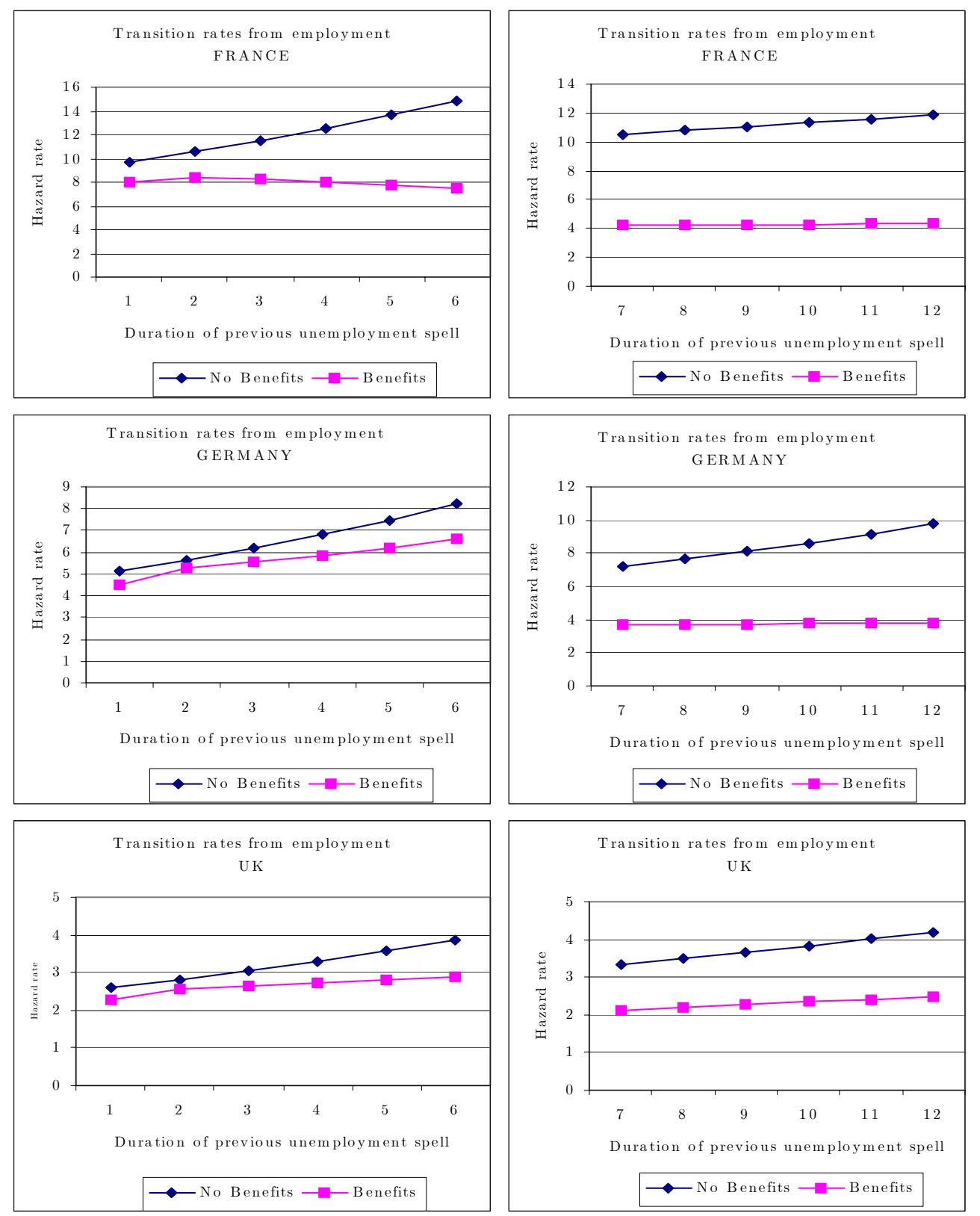

Figure 5: Estimated employment hazard rates by country and benefits for short-term and medium-term unemployed 
Table 1: Transitions in the sample. Number of workers from unemployment to employment. (Total and by country)

\begin{tabular}{|c|c|c|c|c|c|c|c|c|c|c|}
\hline$\overline{\text { Total }}$ & $\overline{\mathrm{NN}}$ & & $\overline{\mathrm{N}}$ & $\overline{\%}$ & & $\overline{\mathrm{N}}$ & $\overline{\%}$ & & $\overline{\mathrm{N}}$ & $\overline{\%}$ \\
\hline \multirow[t]{5}{*}{$\mathrm{U}$} & 1664 & OLF & 431 & 25.90 & $\mathrm{E}$ & 98 & 22.74 & & & \\
\hline & & & & & $\mathrm{C}$ & 144 & 33.41 & & & \\
\hline & & & & & $\mathrm{U}$ & 189 & 43.85 & $\mathrm{C}$ & 189 & 100.0 \\
\hline & & $\mathrm{E}$ & 1101 & 66.17 & & & & & & \\
\hline & & $\mathrm{C}$ & 132 & 7.93 & & & & & & \\
\hline
\end{tabular}

\begin{tabular}{|c|c|c|c|c|c|c|c|c|c|c|}
\hline France & $\mathrm{N}$ & & $\mathrm{N}$ & $\%$ & & $\mathrm{~N}$ & $\%$ & & $\mathrm{~N}$ & $\%$ \\
\hline \multirow[t]{5}{*}{$\mathrm{U}$} & 507 & OLF & 147 & 28.99 & $\mathrm{E}$ & 32 & 21.76 & & & \\
\hline & & & & & C & 21 & 14.29 & & & \\
\hline & & & & & $\mathrm{U}$ & 94 & 63.95 & $\mathrm{C}$ & 94 & 100.0 \\
\hline & & $\mathrm{E}$ & 316 & 62.33 & & & & & & \\
\hline & & C & 44 & 8.68 & & & & & & \\
\hline
\end{tabular}

\begin{tabular}{lllllllllll}
\hline Germany & $\mathrm{N}$ & & $\mathrm{N}$ & $\%$ & & $\mathrm{~N}$ & $\%$ & & $\mathrm{~N}$ & $\%$ \\
\hline \multirow{3}{*}{$\mathrm{U}$} & \multirow{2}{*}{785} & $\mathrm{OLF}$ & 204 & 25.98 & $\mathrm{E}$ & 41 & 21.10 & & & \\
& & & & & $\mathrm{C}$ & 106 & 51.96 & & & \\
& & & & & $\mathrm{U}$ & 57 & 27.94 & $\mathrm{C}$ & 57 & 100.0 \\
& & & & & & & & & & \\
& & $\mathrm{E}$ & 511 & 65.10 & & & & & & \\
& & $\mathrm{C}$ & 70 & 8.92 & & & & & &
\end{tabular}

\begin{tabular}{|c|c|c|c|c|c|c|c|c|c|c|}
\hline UK & $\mathrm{N}$ & & $\mathrm{N}$ & $\%$ & & $\mathrm{~N}$ & $\%$ & & $\mathrm{~N}$ & $\%$ \\
\hline \multirow[t]{5}{*}{$\mathrm{U}$} & 372 & OLF & 80 & 21.51 & $\mathrm{E}$ & 25 & 31.25 & & & \\
\hline & & & & & $\mathrm{C}$ & 17 & 21.25 & & & \\
\hline & & & & & $\mathrm{U}$ & 38 & 47.50 & C & 38 & 100.0 \\
\hline & & $\mathrm{E}$ & 274 & 73.36 & & & & & & \\
\hline & & $\mathrm{C}$ & 18 & 4.84 & & & & & & \\
\hline
\end{tabular}


Table 2: Sample statistics (Means of variables)

\begin{tabular}{llll}
\hline \hline & France & Germany & UK \\
\hline Number of Obs. & 507 & 785 & 372 \\
Receiving benefits at entry into unemployment & 0.45 & 0.66 & 0.30 \\
& & & \\
Higher education & 0.25 & 0.23 & 0.50 \\
Secondary education & 0.13 & 0.58 & 0.16 \\
Less than sec. education & 0.62 & 0.19 & 0.34 \\
Age (years) & 33.35 & 39.0 & 36.8 \\
Married & 0.37 & 0.58 & 0.47 \\
\hline
\end{tabular}

Table 3: Sample statistics by benefits (Means of variables)

\begin{tabular}{lllllll}
\hline \hline & \multicolumn{2}{c}{ France } & \multicolumn{2}{c}{ Germany } & UK \\
\hline & Benefits & No Benefits & Benefits & No Benefits & Benefits & No Benefits \\
\hline Number of obs. & 232 & 275 & 523 & 262 & 115 & 257 \\
& & & & & & \\
Higher education & 0.18 & 0.31 & 0.22 & 0.25 & 0.38 & 0.56 \\
Secondary education & 0.14 & 0.13 & 0.57 & 0.59 & 0.19 & 0.14 \\
Less than sec. education & 0.68 & 0.56 & 0.21 & 0.16 & 0.43 & 0.30 \\
Age (years) & 38.0 & 29.36 & 41.2 & 34.8 & 39.0 & 35.7 \\
Married & 0.49 & 0.28 & 0.64 & 0.46 & 0.53 & 0.44 \\
\hline
\end{tabular}


Table 4: Unemployment insurance benefit system

\begin{tabular}{|c|c|c|}
\hline & \multicolumn{2}{|c|}{ Unemployment Insurance } \\
\hline & Employment Conditions & Replacement Rate \\
\hline & & $\%$ of previous gross earnings \\
\hline France & 4 months in the last 8 months & 75 \\
\hline Germany & 360 days in 3 years & 60 \\
\hline \multirow[t]{2}{*}{ United Kingdom } & - & 30 \\
\hline & \multicolumn{2}{|c|}{ Unemployment Assistance } \\
\hline France & Exhausting UI and & Flat \\
\hline & 5 years in last 10 years & \\
\hline Germany & $\begin{array}{l}\text { Exhausting UI and } 6 \text { months } \\
\text { in the last year }\end{array}$ & 53 \\
\hline United Kingdom & - & Flat \\
\hline
\end{tabular}

Table 5: Duration of UI and UA benefit entitlements in 1996

\footnotetext{
France: maximum of 27 months insurance (depending on age and employment record) and then maximum of 33 months at declining rate every 4 months followed by the Allocation de solidarite specifique (unlimited).

Germany: 6-12 or 32 months (depending on age and employment record) followed by unlimited unemployment assistance.

United Kingdom: 12 months insurance, then unemployment assistance

Source: OECD Employment Outlook 1996, chart 2.3
} 
Table 6: Estimation results for transition out of unemployment (By country)

\begin{tabular}{|c|c|c|c|}
\hline & France & Germany & UK \\
\hline Benefit recipient (Ref: Non-recipient) & $-.660(.092)^{* * *}$ & $-.935(.077)^{* * *}$ & $-.642(.107)^{* * *}$ \\
\hline \multicolumn{4}{|l|}{ Education ( Ref: Less than 2nd level) } \\
\hline Third level & $-.194(.113)^{*}$ & $.517(.114)^{* * *}$ & $.188(.115)^{*}$ \\
\hline 2nd level of secondary & $-.036(.122)$ & $.461(.101)^{* * *}$ & $.030(.149)$ \\
\hline \multicolumn{4}{|l|}{ Age Groups (Ref: 50-60) } \\
\hline $20-25$ & $1.62(.228)^{* * *}$ & $.987(.138)^{* * *}$ & $.368(.160)^{* *}$ \\
\hline $26-29$ & $1.45(.219)^{* * *}$ & $.986(.139)^{* * *}$ & $.254(.177)$ \\
\hline $30-39$ & $1.26(.207)^{* * *}$ & $.843(.114)^{* * *}$ & $.208(.160)$ \\
\hline $40-49$ & $1.09(.214)^{* * *}$ & $.622(.132)^{* * *}$ & $-.026(.149)$ \\
\hline \multicolumn{4}{|l|}{ Spouse's Status (Ref: Single) } \\
\hline Unemployed & $.270(.186)$ & $.530(.143)^{* * *}$ & $-.746(.322)^{* *}$ \\
\hline Employed & $.381(.122)^{* * *}$ & $.411(.092)^{* * *}$ & $.284(.121)^{* *}$ \\
\hline Inactive & $.164(.138)$ & $.280(.124)^{* *}$ & $-.106(.141)$ \\
\hline No of Kids & $-.025(.032)$ & $-.019(.033)$ & $-.031(.041)$ \\
\hline \multicolumn{4}{|l|}{ Duration Dependence (Ref: Month 1) } \\
\hline Dur 2 & $-.214(.173)$ & $-.106(.149)$ & $.111(.166)$ \\
\hline Dur 3 & $-.152(.181)$ & $.242(.144)^{*}$ & $-.197(.214)$ \\
\hline Dur 4 & $-.664(.244)^{* * *}$ & $.006(.173)$ & $-.288(.234)$ \\
\hline Dur 5 & $-.233(.199)$ & $-.103(.178)$ & $-.610(.272)^{* *}$ \\
\hline Dur 6 & $.110(.185)$ & $-.098(.195)$ & $-.382(.257)$ \\
\hline Dur 7 & $-.297(.222)$ & $-.137(.198)$ & $-.670(.302)^{* *}$ \\
\hline Dur 8 & $-1.07(.343)^{* * *}$ & $-.031(.204)$ & $-.876(.341)^{* *}$ \\
\hline Dur 9 & $-.509(.273)^{*}$ & $-.150(.225)$ & $-.424(.287)$ \\
\hline Dur 10 & $-1.52(.457)^{* * *}$ & $-.656(.300)^{* *}$ & $-.915(.387)^{* *}$ \\
\hline Dur 11 & $-.619(.301)^{* *}$ & $-.518(.284)^{*}$ & $-.593(.344)^{*}$ \\
\hline Dur 12 & $-.306(.268)$ & $.250(.211)$ & $-.917(.417)^{* *}$ \\
\hline Dur 13 & $-.396(.299)$ & $-.392(.298)$ & $-.858(.416)^{* *}$ \\
\hline Dur 14 & $-.293(.291)$ & $-.857(.382)^{* *}$ & $-.796(.396)^{* *}$ \\
\hline Dur 15 & $-.072(.291)$ & $-.670(.365)^{*}$ & $-.858(.438)^{* *}$ \\
\hline Dur 16 & $-.564(.386)$ & $-.311(.315)$ & $-1.23(.577)^{* *}$ \\
\hline Dur 17 & $-.241(.333)$ & $-.877(.413)^{* *}$ & $-.465(.405)$ \\
\hline Dur 18 & $-.723(.447)$ & $-.548(.354)$ & $-1.04(.575)^{*}$ \\
\hline Dur 19 & $-.470(.408)$ & $-.364(.336)$ & $-1.40(.708)^{* *}$ \\
\hline Dur 20 & $-.381(.417)$ & $-.534(.388)$ & $-.280(.411)$ \\
\hline Dur 21 & $-.710(.499)$ & $-.808(.446)^{*}$ & $-.585(.508)$ \\
\hline Dur 22 & $-.208(.404)$ & $-.974(.507)^{*}$ & $-1.89(1.00)^{*}$ \\
\hline Dur 23 & $-.471(.495)$ & $-1.21(.579)^{* *}$ & $-1.18(.699)^{*}$ \\
\hline Dur 24 & $-1.44(.244)^{* * *}$ & $-1.93(.184)^{* * *}$ & $-1.30(.229)^{* * *}$ \\
\hline Constant & $-2.92(.287)^{* * *}$ & $-2.89(.211)^{* * *}$ & $-2.15(.246)^{* * *}$ \\
\hline No Obs. & 507 & 785 & 372 \\
\hline Log-Likelihood & -1588.08 & -2163.79 & -1176.29 \\
\hline
\end{tabular}

Notes: Significance levels: ${ }^{* *}=$ at $1 \%,{ }^{* *}=$ at $5 \%$ and ${ }^{*}=$ at $10 \%$. Each estimation includes year dummies 
Table 7: Estimation results for transition out of employment (By country)

\begin{tabular}{|c|c|c|c|}
\hline & France & Germany & 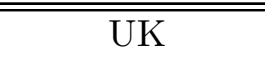 \\
\hline Unemployment Duration & $.002(.010)$ & $.012(.008)$ & $.010(.011)$ \\
\hline Unemployment Duration*Benefits & $-.018(.012)$ & $-.020(.009)^{* *}$ & $-.015(.016)$ \\
\hline \multicolumn{4}{|l|}{ Education ( Ref: Less than 2nd level) } \\
\hline Third level & $-.158(.170)$ & $-.380(.182)^{* *}$ & $-.209(.177)$ \\
\hline 2nd level of secondary & $-.675(.244)^{* * *}$ & $-.021(.139)$ & $-.059(.246)$ \\
\hline \multicolumn{4}{|l|}{ Age Groups (Ref: 50-60) } \\
\hline $20-25$ & $-.087(.287)$ & $-.454(.177)^{* * *}$ & $.358(.274)$ \\
\hline $26-29$ & $-.271(.302)$ & $-.466(.172)^{* * *}$ & $.289(.273)$ \\
\hline $30-39$ & $-.257(.250)$ & $-.557(.143)^{* * *}$ & $.144(.267)$ \\
\hline $40-49$ & $-.166(.257)$ & $-.338(.139)^{* *}$ & $.295(.252)$ \\
\hline \multicolumn{4}{|l|}{ Spouse's Status (Ref: Single) } \\
\hline Unemployed & $.283(.232)$ & $.116(.185)$ & $-.330(.680)$ \\
\hline Employed & $-.248(.186)$ & $-.062(.124)$ & $-.225(.198)$ \\
\hline Inactive & $-.117(.231)$ & $-.009(.155)$ & $-.002(.220)$ \\
\hline No of Kids & $.037(.039)$ & $-.015(.041)$ & $.015(.074)$ \\
\hline \multicolumn{4}{|l|}{ Type of Job } \\
\hline Regular Job (Self-Employed) & $.394(.446)$ & $1.20(.416)^{* * *}$ & $.415(.241)^{*}$ \\
\hline \multicolumn{4}{|l|}{ Duration Dependence (Ref: Month 1) } \\
\hline Month 2 & $.387(.248)$ & $-.218(.346)$ & $.123(.322)$ \\
\hline Month 3 & $.052(.290)$ & $.236(.309)$ & $-.499(.411)$ \\
\hline Month 4 & $-.352(.349)$ & $-.180(.354)$ & $-.533(.431)$ \\
\hline Month 5 & $-.257(.338)$ & $-.388(.384)$ & $-1.08(.543)^{* *}$ \\
\hline Month 6 & $-.818(.417)^{* *}$ & $.242(.321)$ & $-.393(.413)$ \\
\hline Month 7 & $-.105(.337)$ & $-.095(.361)$ & $-1.25(.615)^{* *}$ \\
\hline Month 8 & $-1.15(.533)^{* *}$ & $.465(.315)$ & $-.708(.497)$ \\
\hline Month 9 & $-.835(.485)^{*}$ & $1.03(.281)^{* * *}$ & $-.917(.544)^{*}$ \\
\hline Month 10 & $-.428(.415)$ & $.796(.306)^{* * *}$ & $-2.24(1.02)^{* *}$ \\
\hline Month 11 & $-.154(.378)$ & $.823(.311)^{* * *}$ & $-.099(.411)$ \\
\hline Month 12 & $-.703(.480)$ & $.619(.337)^{*}$ & $-1.40(.738)^{*}$ \\
\hline Month 13 & $-.834(.528)$ & $.572(.352)^{*}$ & $-.901(.620)$ \\
\hline Month 14 & $-1.09(.596)^{*}$ & $-.128(.463)$ & $-2.11(1.02)^{* *}$ \\
\hline Month 15 & $-2.38(.284)^{* * *}$ & $-.738(.618)$ & $-2.10(1.02)^{* *}$ \\
\hline Month 16 & & $-.221(.497)$ & $-1.29(.741)^{*}$ \\
\hline Month 17 & & $-1.34(.263)^{* * *}$ & $-2.71(.312)^{* * *}$ \\
\hline Constant & $-2.65(.683)^{* * *}$ & $-3.75(.557)^{* * *}$ & $-2.81(.519)^{* * *}$ \\
\hline No Obs. & 348 & 552 & 299 \\
\hline Log-Likelihood & -911.35 & -1477.46 & -624.91 \\
\hline
\end{tabular}

Notes: Significance levels: ${ }^{* *}=$ at $1 \%,{ }^{* *}=$ at $5 \%$ and ${ }^{*}=$ at $10 \%$. Each estimation includes year dummies 
Table 8: Effect of previous unemployment duration on employment hazard (By country)

\begin{tabular}{lccc}
\hline \hline & France & Germany & UK \\
\hline UnDur (0-6) & $.031(.044)$ & $.067(.043)$ & $.051(.062)$ \\
UnDur (6-12) & $-.003(.027)$ & $.047(.025)^{*}$ & $.028(.030)$ \\
UnDur (12-24) & $.007(.017)$ & $.039(.027)$ & $.013(.016)$ \\
Un Dur (24+) & $-.001(.014)$ & $.007(.011)$ & $.010(.013)$ \\
& & & \\
UnDur*Benefits (0-6) & $-.109(.044)^{* *}$ & $-.022(.036)$ & $-.055(.072)$ \\
UnDur*Benefits $(6-12)$ & $-.007(.035)$ & $-.061(.024)^{* *}$ & $-.013(.035)$ \\
UnDur*Benefits $(12-24)$ & $-.025(.018)$ & $-.028(.028)$ & $-.034(.026)$ \\
UnDur*Benefits $(24+)$ & $-.002(.019)$ & $-.018(.015)$ & $-.002(.021)$ \\
& & & \\
Constant & $-2.71(.707)^{* * *}$ & $-3.87(.580)^{* * *}$ & $-2.88(.527)^{* * *}$ \\
No Obs. & 348 & 552 & 299 \\
Log-Likelihood & -909.37 & -1474.04 & -624.20 \\
& & & \\
\hline
\end{tabular}

Notes: Significance levels: $* * *=$ at $1 \%, * *=$ at $5 \%$ and $*=$ at $10 \%$

Each estimation includes year dummies

Table 9: Expected duration of unemployment and employment by benefits

Panel A

\begin{tabular}{lll}
\hline \hline \multicolumn{3}{l}{ Expected Unemployment Duration (months) } \\
\hline & No Benefits & Benefits \\
\hline & & \\
France & 8.24 & 16.75 \\
Germany & 6.49 & 12.27 \\
UK & 7.54 & 11.38 \\
\hline
\end{tabular}

Panel B

Expected Employment Duration (months)

(at expected unemployment duration of each group)

No Benefits Benefits

\begin{tabular}{lll}
\hline & & \\
France & 37.43 & 43.71 \\
Germany & 25.47 & 34.84 \\
UK & 36.53 & 37.20 \\
\hline
\end{tabular}

Note: Reference person: secondary education, 30-39 years old, single, no kids, regular job in 1996 